\title{
25804
}

\section{Broadband Seismic Imaging, a Case Study Offshore Malaysia}

W.K. Chia (PCSB), A.R. Sharmizi (PCSB), Y. Guo (CGG Services (Singapore) Pte.Ltd), Y. Li (CGG Services (Singapore) Pte.Ltd) \& N. Li* (CGG Services (Singapore) Pte.Ltd.)

\section{SUMMARY}

We share the experiences in processing broadband seismic data acquired using variable-depth streamers, offshore Malaysia. The $6000 \mathrm{~km} 2$ survey is in a shallow water area (depth from 30 to $75 \mathrm{~m}$ ). Gas pinnacles at water bottom further limiting the maximum towable cable depth.

Four different cable profiles were used during acquisition. Despite of this, almost identical broadband spectra were achieved after deghosting. Redatum inside deghosting algorithm produced seamless data volumes for subsequent processing. Shallow water demultiple is still effective. Moreover, a sequence of cable deghosting before demultiple gives optimum result, because deghosting broadens spectra and helps to model and remove low-frequency multiples better.

The final PSTM stack shows high resolution and fidelity, with great details and easy-identified geological features. The reflectors are side-lobe free, maintaining usable frequency from 3 to $100 \mathrm{~Hz}$. Top of basement and intra-basement fractures are also well imaged. 
In this paper we share the experiences in processing broadband seismic data acquired using variabledepth streamers, offshore Malaysia. The $6000 \mathrm{~km}^{2}$ survey is in a shallow water area, with water depth varying from 30 to $75 \mathrm{~m}$. There are also gas pinnacles at water bottom, further limiting the maximum towable cable depth. The shallow water setting poses unique challenges to both acquisition and processing.

Depending on the water depth, four different cable profiles were used in the survey. These are 6 to $35 \mathrm{~m}, 6$ to $25 \mathrm{~m}, 6$ to $20 \mathrm{~m}$ and 6 to $15 \mathrm{~m}$. We show that despite the difference in cable profiles, almost identical broadband spectra were achieved after deghosting. The deghosting also included redatum to a common cable depth to produce seamless data volumes for subsequent processing.

A key issue in all shallow water data processing is the attenuation of multiples. We present our demultiple workflow and show that in the case of variable depth streamer acquisition, shallow water demultiple is just as effective as in conventional data. We also demonstrate, through detailed analysis, that a sequence of cable deghosting before demultiple gives optimum result, because deghosting broadens spectra and helps to model and remove low-frequency multiples better.

The final result from the processing is of high resolution, both vertically and laterally, and high fidelity. Figure 1 shows a section from the final PSTM stack. In the shallower part, it shows great details and vivid textures for easy identification of geological features. The finely layered reflectors are side-lobe free, allowing very precise interpretation without ambiguity. The usable frequency is from 3 to $100 \mathrm{~Hz}$. The lateral resolution is also high. In the deeper part, the top of basement and intra-basement fractures are well imaged thanks to the deep penetration of broadband acquisition.

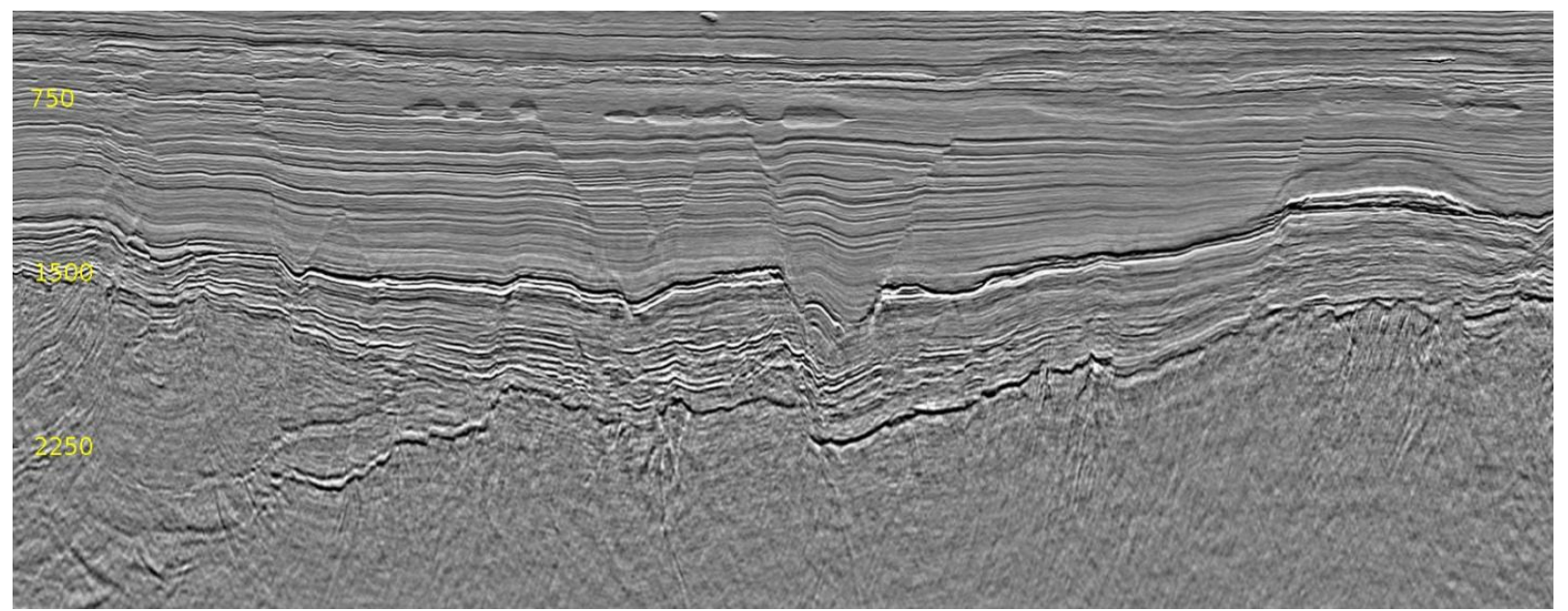

Figure 1.A section in the PSTM stack exhibiting high resolution. 